Check for updates

Cite this: Chem. Commun., 2017, 53,5200

Received 24th March 2017,

Accepted 19th April 2017

DOI: $10.1039 / \mathrm{c} 7 \mathrm{cc} 02245 \mathrm{j}$

rsc.li/chemcomm

\section{A chiral member of the family of organic hexameric cages $\dagger$}

\author{
M. Wierzbicki, A A. Gtowacka, \$ M. P. Szymański and A. Szumna (DD*
}

A cubic nanocage ( $O$ symmetry) that exhibits inherent chirality and has a covalent, rigid skeleton with molecule-sized entrance portals was obtained by means of dynamic covalent chemistry using a reaction between aldehyde-functionalized resorcin[4]arene and hydrazine.

Aggregation of multiple identical building blocks is the most cost-effective strategy for preparation of complex structures from the perspective of molecular economy. It minimizes the number of units to be synthesized while maximizing the number of effective interactions between them. In this regard viral capsids are spectacular examples proving the operational effectiveness of this concept - their complex structures are assembled from many identical protein molecules, allowing consumption of a minimal amount of genetic information. Many nanosized organic capsules $^{1}$ are also constructed by connecting identical building blocks to produce tetrahedral, ${ }^{2-6}$ cubic, ${ }^{7-9}$ octahedral, ${ }^{10}$ dodecahedral $^{11}$ or icosahedral capsules ${ }^{12,13}$ (geometries of Platonic solids). Among them resorcinarene-based hexamers attract attention not only due to their easy synthesis and aesthetic design, but also because they have proven to be exceptional for stabilizing fleeting reactive intermediates, ${ }^{14}$ accelerating, ${ }^{15-17}$ or changing regiochemistry $^{18}$ and product distributions ${ }^{19-22}$ of reactions, and blocking non-radiative decays for luminescent molecules. ${ }^{23}$ Chirality of organic cages would open new research directions towards asymmetric applications, but the number of such molecules is limited. ${ }^{2,3,24,25}$ In this paper we present a new member of the family of organic nanocages that has unique features, originating from its chirality, covalent, rigid skeleton and presence of moleculesized portals.

We have previously shown that tetraformylresorcin[4]arene $\mathbf{1}^{26}$ reacts easily with monofunctional amines and hydrazides leading to formation of respective imines (quantitatively

Institute of Organic Chemistry, Polish Academy of Sciences, Kasprzaka 44/52, 01-22 Warsaw, Poland. E-mail: agnieszka.szumna@icho.edu.pl

$\dagger$ Electronic supplementary information (ESI) available: Experimental procedures, spectra, optimization and TD DFT results. CCDC 1539623. For ESI and crystallographic data in CIF or other electronic format see DOI: $10.1039 / \mathrm{c} 7 \mathrm{cc} 02245 \mathrm{j}$

\$ These authors contributed equally. tautomerized to keto-enamines $)^{27}$ and acylhydrazones. ${ }^{28}$ Both types of products are stabilized by directional seams of intramolecular hydrogen bonds, which, in addition to stabilization, results in inherent chirality of the molecules. ${ }^{29}$ Currently, we used a bifunctional semi-rigid building block - hydrazine expecting formation of covalently connected cages (Fig. 1). Reaction between tetraformylresorcin[4] arene 1 (1 equiv.) and hydrazine ( 2 equiv.) in different organic solvents was unsuccessful

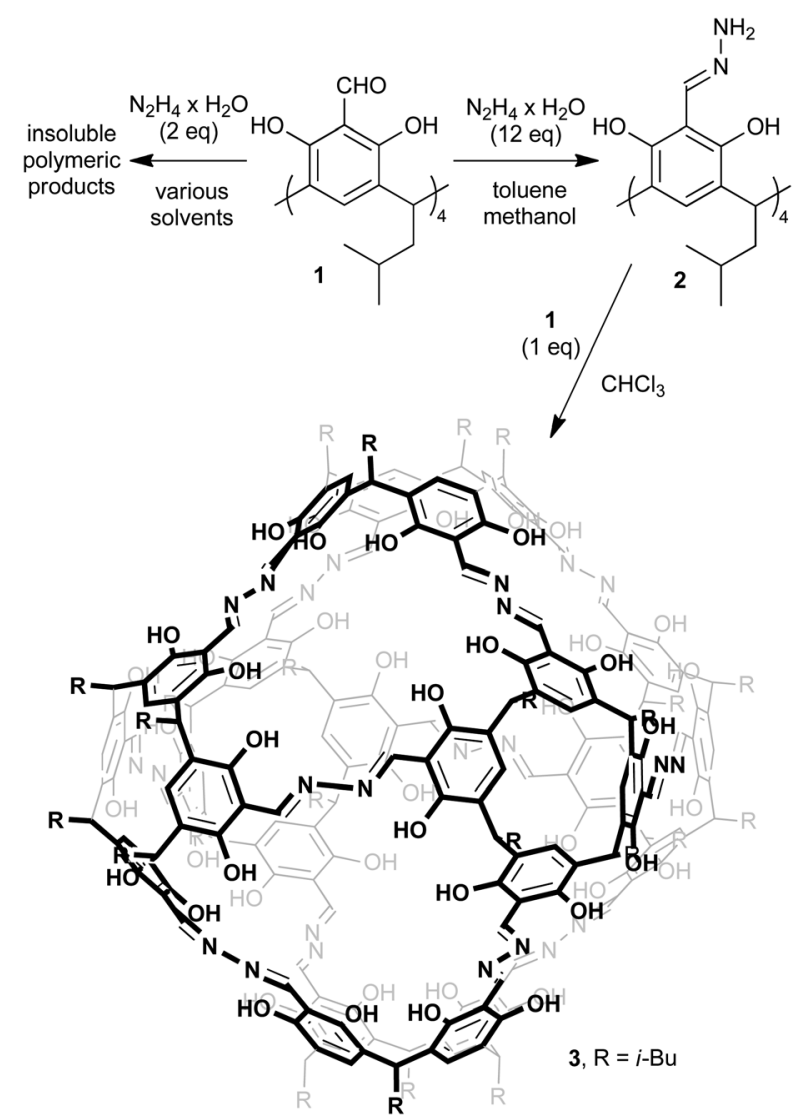

Fig. 1 The synthesis and chemical structure of the hexameric capsule $\mathbf{3}$. 
(a)
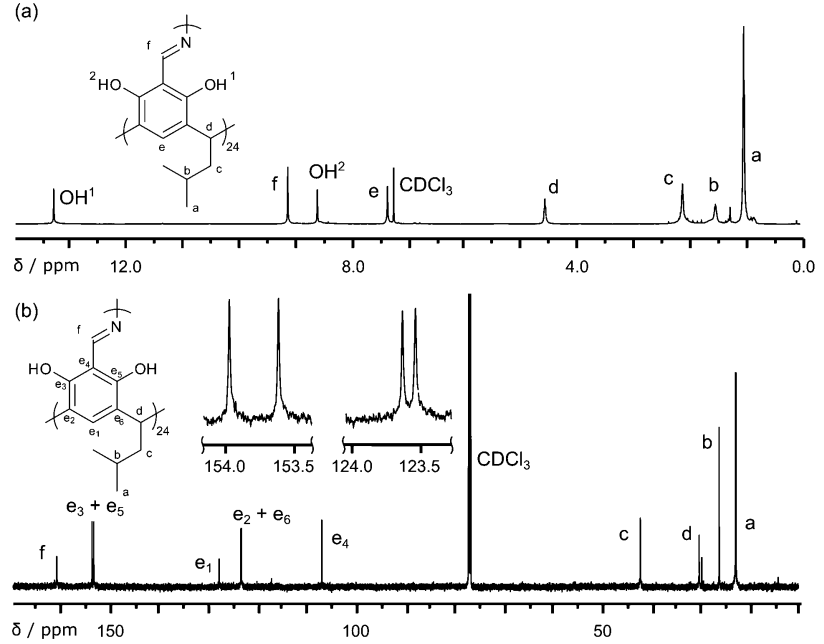

Fig. 2 (a) ${ }^{1} \mathrm{H}$ NMR spectrum $\left(\mathrm{CDCl}_{3}, 600 \mathrm{MHz}, 298 \mathrm{~K}\right)$ and (b) ${ }^{13} \mathrm{C} \mathrm{NMR}$ spectrum of $3\left(\mathrm{CDCl}_{3}, 150 \mathrm{MHz}\right)$

and resulted in formation of insoluble polymeric species. However, a two-step procedure that involved synthesis of tetrahydrazone 2 using an excess of hydrazine (12 equiv.) and subsequent reaction between 1 and 2 led to formation of hexameric condensation product 3 in quantitative yield.

The structure of 3 was confirmed by mass spectrometry, NMR (including DOSY) and crystallography (see ESI $\dagger$ ). ${ }^{1} \mathrm{H}$ NMR spectrum of 3 in $\mathrm{CDCl}_{3}$ (Fig. 2a) reveals cubic symmetry of the molecule with one unit based on resorcinol ring being symmetry-independent ( $O$ point group in the Schoenflies notation and 432 group in the Hermann-Mauguin notation). Due to directionality of hydrazone linkers and the hydrogen bonding system the two hydroxyl groups give separate ${ }^{1} \mathrm{H}$ NMR signals and six aromatic signals are present in ${ }^{13} \mathrm{C}$ NMR (Fig. 2b). Based on $2 \mathrm{D}$ spectra the signal at $13.3 \mathrm{ppm}$ was attributed to the $\mathrm{OH}$ group engaged in an intramolecular hydrogen bond with the nitrogen atom, while the signal at $8.6 \mathrm{ppm}$ originates from the $\mathrm{OH}$ group forming a hydrogen bond between neighboring resorcinol rings.

Single crystals of 3 were obtained by slow evaporation of a methanol/toluene solution. The X-ray structure confirms the constitution and the symmetry claimed based on the solution data (Fig. 3a). Six resorcinarene skeletons are covalently linked by twelve hydrazone groups. The external diameter of the capsule is approximately $3.0 \mathrm{~nm}$ which corresponds exactly to the $3.0 \mathrm{~nm}$ diameter calculated using Stokes-Einstein equation based on diffusion coefficient in solution (diffusion coefficient for 3 is $2.7 \times 10^{-10} \mathrm{~m}^{2} \mathrm{~s}^{-1}$ in $\mathrm{CDCl}_{3}$ at $298 \mathrm{~K}$ ). In the solid state the molecule of 3 exhibits $C_{3}$ symmetry with two resorcin[4]arene skeletons being a crystallographically symmetry-independent part. However, the molecular symmetry of the cage is very close to $O$ symmetry found in solution. Intramolecular hydrogen bonds are formed between hydroxyl groups and nitrogen atoms and between the neighboring aromatic groups (total of 48 hydrogen bonds per capsule). These hydrogen bonds, together with a partial double bond character of $\mathrm{C}-\mathrm{N}$ and $\mathrm{N}-\mathrm{N}$ bonds rigidify the structure and stabilize the co-planar arrangement of hydrazone linkers with (a)

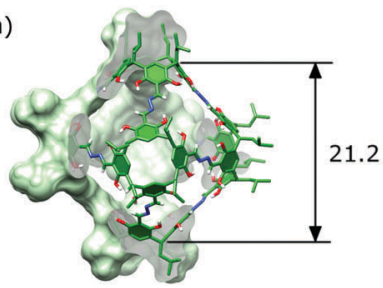

(b)

(c)

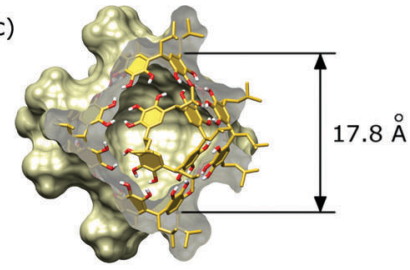

(e)

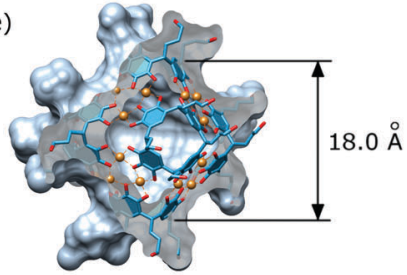

(f)

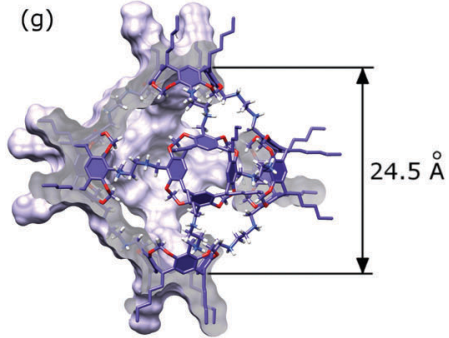

(d)
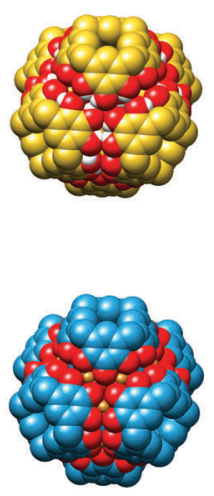

(h)

Fig. 3 The structures of: ( $a$ and b) $\mathbf{3}$ (X-ray structure, this work); (c and d) hydrogen bonded hexamer 4 (refcode: $C A N Q A J)$; (e and f) coordination hexamer 5 (refcode: GALMOW); ( $g$ and $\mathrm{h}$ ) imine-based hexamer $\mathbf{6}$ (modelled structure, courtesy of Prof. R. Warmuth).

respect to aromatic rings and also the planar s-trans conformation of all $\mathrm{N}-\mathrm{N}$ bonds (dihedral angles $\mathrm{C}_{\mathrm{ar}}-\mathrm{C}_{\mathrm{ar}}-\mathrm{C}=\mathrm{N}$ do not exceed $5^{\circ}$ and dihedral angles $\mathrm{C}=\mathrm{N}-\mathrm{N}=\mathrm{C}$ are in the range of $178-170^{\circ}$ ). This is in sharp contrast with the previously reported imine hexamer published by the group of Warmuth, ${ }^{9}$ in which the imine bonds are dynamic and substantially twisted in respect to the resorcin[4]arene skeleton.

Chirality of 3 comes from the pinwheel-shaped directional arrangement of hydrazone groups, that exhibit the same helical twist in each resorcinarene unit. This chiral pattern is also in agreement with the symmetry of capsule 3 observed in solution. Although chirality of 3 is in principle of conformational origin, we expect that enantiomers are stable because their racemization would require either concerted rotation around all single bonds within the capsule core or covalent breakage of at least half of the hydrazone covalent bonds. Both processes are unlikely due to rigidity of the structure and because of relatively high resistance of hydrazone bonds against hydrolysis as compared with other dynamic bonds. ${ }^{30}$ Partial separation of enantiomers was achieved using analytical chiral HPLC with a CD detector (Fig. 4). The CD spectrum for a partially resolved 
(a)

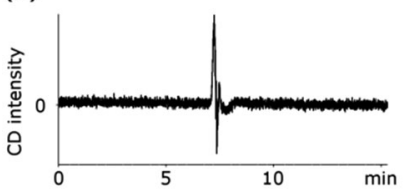

(b)

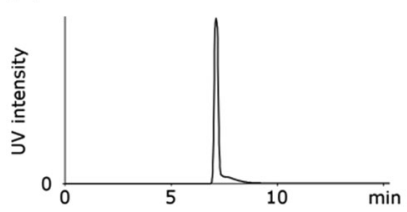

(c)

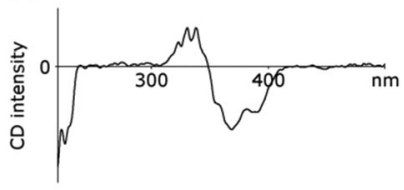

(d)

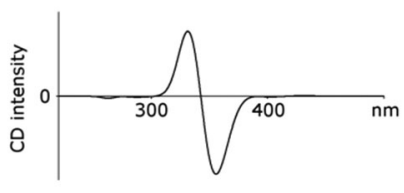

Fig. 4 Chiral HPLC analysis (Chiralpak IC column with 8\% DCM in hexane as the mobile phase) of 3 : (a) HPLC chromatogram with CD signal detection at $340 \mathrm{~nm}$; (b) HPLC chromatogram with UV signal detection at $340 \mathrm{~nm}$; (c) experimental CD spectrum recorded for the first eluting peak; (d) theoretically calculated CD spectrum for a partial model compound (TD DFT B3LYP/6$31 \mathrm{G}(\mathrm{d})$, see $\mathrm{ES} \mid \dagger)$.

first-eluting peak is bisignate and it is in a qualitative agreement with a theoretically calculated spectrum for a model structure, being a representative part of hexamer 3 (TD DFT B3LYP/6-31G(d) in Gaussian, ${ }^{31}$ see $\left.\mathrm{ESI}^{\dagger}\right)$. The CD spectrum of the second enantiomer could not be recorded due to substantial overlap of peaks. However, the chromatogram obtained by monitoring of a CD signal at $340 \mathrm{~nm}$ indicates that the sign of a CD signal for the second-eluting peak is opposite to the sign of the first-eluting peak, in agreement with their enantiomeric relationship.

The cavity of 3 has an intermediate size between the wellknown pyrogallol[4]arene capsule ${ }^{8}$ sealed by hydrogen bonds (4, Fig. 3b) or coordination bonds ${ }^{32}$ (5, Fig. $\left.3 \mathrm{c}\right)$ and the iminebased capsule reported by the group of Warmuth (6, Fig. $3 \mathrm{~d}) .^{9,33}$ Calculated internal volume of cavity for 3 is $2283 \AA^{3}$ as compared with $1318 \AA^{3}$ for $4,1201 \AA^{3}$ for 5 and $3153 \AA^{3}$ for 6 (all calculated using a $1.0 \AA$ probe in OLEX2, ${ }^{34}$ openings were filled with layers of hydrogen atoms). The diagonals of 3 measured between the bottoms of opposite the resorcinarene bowls are approximately 3 $\AA$ longer than for $\mathbf{4}$ and $\mathbf{5}$ (analysis of available crystal structures) and $3 \AA$ shorter than for modelled structure 6 .

Van der Waals representation of 3 reveals the presence of eight portals located at $C_{3}$ axes of the hexamer (Fig. 3b). The portals are rimmed by $\mathrm{OH}$ groups and their sizes are sufficient
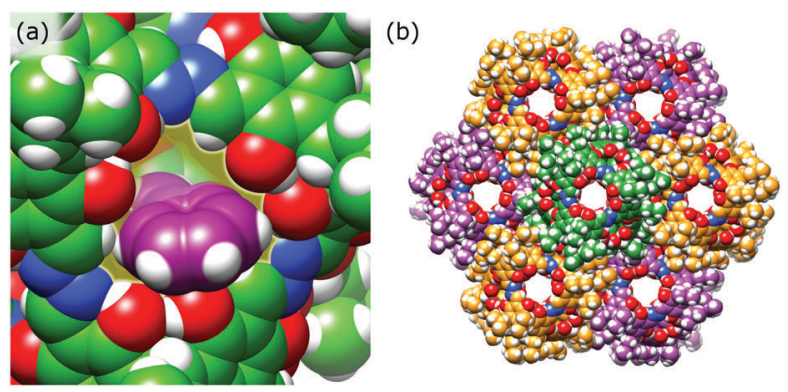

Fig. 5 (a) vdW representation of a toluene molecule (modelled) passing through one of the portals in the X-ray structure of 3; (b) window-towindow packing along the crystallographic $c$ axis (multiple layers of molecules are present).

for passage of small flexible aliphatic molecules or aromatic rings. For example, a geometric fit indicates that benzene molecule can pass through the portal (Fig. 5a). This is in sharp contrast with capsules 4 and 5 that do not have portals and, therefore, they have to dissociate (partially or fully) for guest uptake. Indeed, it has been shown that guest uptake for $\mathbf{4}$ is hedged by a high kinetic barrier, ${ }^{35-37}$ while it is completely blocked for coordination-based capsule 5. For capsule 6 entrance portals are inevitably present, however, the capsule is much more conformationally labile and complexation studies have not been reported. For capsule 3 complexation studies indicate that the capsule interacts with alkylammonium and $N$-alkyl pyridinium cations. Detailed studies on complexation thermodynamics and kinetics are underway.

Considering the rigid skeleton of 3 , the capsule can be considered as a shape-persistent cage possessing an intrinsic porosity also in the solid state due to presence of internal and external cavities. ${ }^{38-44}$ Analysis of packing in the crystal network indicates that although the capsules are relatively dense-packed with small intercapsular voids, they pack in a window-towindow arrangement (Fig. 5b). Therefore the internal cavities of the capsules are interconnected trough portals and form channels rimmed by hydroxyl groups and interdigitating alkyl chains. The calcVoid (OLEX2) procedure indicates that all crystallographic directions can be penetrated by a sphere of 5.2 A diameter. This channel-type structure can potentially lead to interesting solid-state sorption properties.

In conclusion, we have obtained a new covalent hexameric cage exhibiting the symmetry of one of the Platonic solids - a cube. The synthesis involves hydrazone formation reaction. The capsule is inherently chiral due to directional arrangement of hydrazone groups and its rigid structure is stabilized by hydrogen bonds. It possesses entrance portals that allow for passage of small molecules.

This work was supported by the National Science Center (2013/09/B/ST5/01026) and the Wroclaw Centre for Networking and Supercomputing (grant no. 299). We would like to acknowledge Dr Barbara Leśniewska for crystallographic data collection and Dr Aleksandra Butkiewicz for CD measurements.

\section{Notes and references}

1 G. Zhang and M. Mastalerz, Chem. Soc. Rev., 2014, 43, 1934.

2 P. Skowronek and J. Gawronski, Org. Lett., 2008, 10, 4755.

3 T. Hasell, S. Y. Chong, K. E. Jelfs, D. J. Adams and A. I. Cooper, J. Am. Chem. Soc., 2012, 134, 588.

4 T. Tozawa, J. T. A. Jones, S. I. Swamy, S. Jiang, D. J. Adams, S. Shakespeare, R. Clowes, D. Bradshaw, T. Hasell, S. Y. Chong, C. Tang, S. Thompson, J. Parker, A. Trewin, J. Bacsa, A. M. Z. Slawin, A. Steiner and A. I. Cooper, Nat. Mater., 2009, 8, 973.

5 S. I. Swamy, J. Bacsa, J. T. A. Jones, K. C. Stylianou, A. Steiner, L. K. Ritchie, T. Hasell, J. A. Gould, A. Laybourn, Y. Z. Khimyak, D. J. Adams, M. J. Rosseinsky and A. I. Cooper, J. Am. Chem. Soc., 2010, 132, 12773.

6 X. Liu and R. Warmuth, J. Am. Chem. Soc., 2006, 128, 14120.

7 J. L. Atwood and L. R. MacGillivray, Nature, 1997, 389, 469.

8 T. Gerkensmeier, W. Iwanek, C. Agena, R. Fröhlich, S. Kotila, C. Näther and J. Mattay, Eur. J. Org. Chem., 1999, 2257.

9 X. Liu, Y. Liu, G. Li and R. Warmuth, Angew. Chem., Int. Ed., 2006, 45, 901.

10 P. Skowronek, B. Warżajtis, U. Rychlewska and J. Gawroński, Chem. Commun., 2013, 49, 2524. 
11 Y. He, T. Ye, M. Su, C. Zhang, A. E. Ribbe, W. Jiang and C. Mao, Nature, 2008, 452, 198.

12 C. Zhang, M. Su, Y. He, X. Zhao, P. Fang, A. E. Ribbe, W. Jiang and C. Mao, Proc. Natl. Acad. Sci. U. S. A., 2008, 105, 10665.

13 S. Pasquale, S. Sattin, E. C. Escudero-Adán, M. Martínez-Belmonte and J. de Mendoza, Nat. Commun., 2012, 3, 785.

14 L. Catti, Q. Zhang and K. Tiefenbacher, Synthesis, 2016, 313.

15 Q. Zhang and K. Tiefenbacher, Nat. Chem., 2015, 7, 197.

16 L. Catti and K. Tiefenbacher, Chem. Commun., 2015, 51, 892.

17 G. Bianchini, G. La Sorella, N. Canever, A. Scarso and G. Strukul, Chem. Commun., 2013, 49, 5322.

18 A. Cavarzan, A. Scarso, P. Sgarbossa, G. Strukul and J. N. H. Reek, J. Am. Chem. Soc., 2011, 133, 2848.

19 Q. Zhang and K. Tiefenbacher, J. Am. Chem. Soc., 2013, 135, 16213.

20 G. La Sorella, L. Sperni, G. Strukul and A. Scarso, ChemCatChem, $2015,7,291$.

21 S. Giust, G. La Sorella, L. Sperni, G. Strukul and A. Scarso, Chem. Commun., 2015, 51, 1658.

22 T. M. Bräuer, Q. Zhang and K. Tiefenbacher, Angew. Chem., Int. Ed., 2016, 55, 7698.

23 S. Horiuchi, H. Tanaka, E. Sakuda, Y. Arikawa and K. Umakoshi, Chem. - Eur. J., 2016, 22, 17533.

24 J. Sun, J. L. Bennett, T. J. Emge and R. Warmuth, J. Am. Chem. Soc., 2011, 133, 3268.

25 D. Beaudoin, F. Rominger and M. Mastalerz, Angew. Chem., Int. Ed., 2016, 55, 15599.

26 M. Grajda, M. Wierzbicki, P. Cmoch and A. Szumna, J. Org. Chem., 2013, 78, 11597.

27 H. Jędrzejewska, M. Wierzbicki, P. Cmoch, K. Rissanen and A. Szumna, Angew. Chem., Int. Ed., 2014, 53, 13760.

28 M. Szymański, M. Wierzbicki, M. Gilski, H. Jędrzejewska, M. Sztylko, P. Cmoch, A. Shkurenko, M. Jaskolski and A. Szumna, Chem. - Eur. J., 2016, 22, 3148.

29 H. Jędrzejewska, M. Kwit and A. Szumna, Chem. Commun., 2015, 51, 13799.

30 F. J. Uribe-Romo, C. J. Doonan, H. Furukawa, K. Oisaki and O. M. Yaghi, J. Am. Chem. Soc., 2011, 133, 11478.

31 M. J. Frisch, G. W. Trucks, H. B. Schlegel, G. E. Scuseria, M. A. Robb, J. R. Cheeseman, G. Scalmani, V. Barone, B. Mennucci, G. A. Petersson, H. Nakatsuji, M. Caricato, X. Li, H. P. Hratchian, A. F. Izmaylov,
J. Bloino, G. Zheng, J. L. Sonnenberg, M. Hada, M. Ehara, K. Toyota, R. Fukuda, J. Hasegawa, M. Ishida, T. Nakajima, Y. Honda, O. Kitao, H. Nakai, T. Vreven, J. A. Montgomery, Jr, J. E. Peralta, F. Ogliaro, M. Bearpark, J. J. Heyd, E. Brothers, K. N. Kudin, V. N. Staroverov, R. Kobayashi, J. Normand, K. Raghavachari, A. Rendell, J. C. Burant, S. S. Iyengar, J. Tomasi, M. Cossi, N. Rega, J. M. Millam, M. Klene, J. E. Knox, J. B. Cross, V. Bakken, C. Adamo, J. Jaramillo, R. Gomperts, R. E. Stratmann, O. Yazyev, A. J. Austin, R. Cammi, C. Pomelli, J. W. Ochterski, R. L. Martin, K. Morokuma, V. G. Zakrzewski, G. A. Voth, P. Salvador, J. J. Dannenberg, S. Dapprich, A. D. Daniels, Ö. Farkas, J. B. Foresman, J. V. Ortiz, J. Cioslowski and D. J. Fox, Gaussian 09, Revision D.01, Gaussian, Inc., Wallingford CT, 2009.

32 R. M. McKinlay, G. W. V. Cave and J. L. Atwood, Proc. Natl. Acad. Sci. U. S. A., 2005, 99, 5944.

33 X. Liu and R. Warmuth, J. Am. Chem. Soc., 2006, 128, 14120.

34 O. V. Dolomanov, L. J. Bourhis, R. J. Gildea, J. A. K. Howard and H. Puschmann, J. Appl. Crystallogr., 2009, 42, 339.

35 J. C. Chapin, M. Kvasnica and B. W. Purse, J. Am. Chem. Soc., 2012, 134, 15000.

36 M. Kvasnica, J. C. Chapin and B. W. Purse, Angew. Chem., Int. Ed., 2011, 50, 2244-2248.

37 J. C. Chapin and B. W. Purse, Supramol. Chem., 2014, 7-8, 517.

38 T. Tozawa, J. T. A. Jones, S. I. Swamy, S. Jiang, D. J. Adams, S. Shakespeare, R. Clowes, D. Bradshaw, T. Hasell, S. Y. Chong, C. Tang, S. Thompson, J. Parker, A. Trewin, J. Bacsa, A. M. Z. Slawin, A. Steiner and A. I. Cooper, Nat. Mater., 2009, 8, 973.

39 T. Mitra, K. E. Jelfs, M. Schmidtmann, A. Ahmed, S. Y. Chong, D. J. Adams and A. I. Cooper, Nat. Chem., 2013, 5, 276.

40 J. R. Holst, A. Trewin and A. I. Cooper, Nat. Chem., 2010, 2, 915.

41 M. E. Briggs and A. I. Cooper, Chem. Mater., 2017, 29, 149.

42 C. M. Kane, O. Ugono, L. J. Barbour and K. Travis Holman, Chem. Mater., 2015, 27, 7337.

43 J. Tian, P. K. Thallapally and B. P. McGrail, CrystEngComm, 2012, 14, 1909; M. Mastalerz, Angew. Chem., Int. Ed., 2010, 49, 5042; L. J. Barbour, Chem. Commun., 2006, 1163; J. L. Atwood, L. J. Barbour, A. Jerga and B. L. Schottel, Science, 2002, 298, 1000; G. Zhang and M. Mastalerz, Chem. Soc. Rev., 2014, 43, 1934.

44 G. Zhang, O. Presly, F. White, I. M. Oppel and M. Mastalerz, Angew. Chem., Int. Ed., 2014, 53, 1516. 